Article

\title{
Industrial Electrification and Efficiency: Decomposition Evidence from the Korean Industrial Sector
}

\author{
Jiyong Park ${ }^{1,+}$, Taeyoung Jin ${ }^{1,+} \mathbb{D}$, Sungin Lee ${ }^{1}$ and Jongroul Woo ${ }^{2, * \mathbb{D}}$ \\ 1 Korea Energy Economics Institute, Ulsan 44543, Korea; jiyong.park@keei.re.kr (J.P.); tyjin@keei.re.kr (T.J.); \\ silee@keei.re.kr (S.L.) \\ 2 Energy Environment Policy and Technology, Graduate School of Energy and Environment (KU-KIST Green \\ School), Korea University, Seoul 02841, Korea \\ * Correspondence: jrwoo@korea.ac.kr \\ + These authors contributed equally to this work.
}

Citation: Park, J.; Jin, T.; Lee, S.; Woo, J. Industrial Electrification and Efficiency: Decomposition Evidence from the Korean Industrial Sector. Energies 2021, 14, 5120. https:// doi.org/10.3390/en14165120

Academic Editors: Kostas Kounetas and Mariusz J. Stolarski

Received: 21 July 2021

Accepted: 18 August 2021

Published: 19 August 2021

Publisher's Note: MDPI stays neutral with regard to jurisdictional claims in published maps and institutional affiliations.

Copyright: (c) 2021 by the authors. Licensee MDPI, Basel, Switzerland. This article is an open access article distributed under the terms and conditions of the Creative Commons Attribution (CC BY) license (https:// creativecommons.org/licenses/by/ $4.0 /)$.

\begin{abstract}
For this study, we conducted a decomposition analysis of industrial electricity consumption based on the logarithmic mean Divisia index approach. An empirical dataset consisting of 11 industrial sectors in Korea from 2000 to 2018 was used. The three-factor decomposition equation was extended to include four factors by decomposing the energy intensity effect into electrification and electricity consumption efficiency effects. The empirical results are summarized as follows: The increase in electricity consumption in the Korean industrial sector from 2000 to 2018 is mostly caused by the production effect. While the structure effect decreases electricity consumption, the intensity effect increases it. The key findings indicate that the hidden electrification effect can be confusing to researchers with regard to the intensity effect. The empirical evidence suggests that the intensity effect has a positive effect on electricity consumption induced by the electrification effect, although the efficiency effect continuously decreased electricity consumption. The decomposition results of some sectors show that electrification, rather than the production effect, contributed the most to the increase in electricity consumption. This implies that while replacing fuel with electricity has been successfully achieved in several sectors, there are still challenges regarding increasing energy efficiency and expanding clean electricity generation.
\end{abstract}

Keywords: industrial electricity; electricity consumption efficiency; electrification; South Korea

\section{Introduction}

Climate change is primarily caused by greenhouse gases (GHGs) that are closely related to the energy sector. Significant efforts have been made to mitigate this problem. Following the Paris Agreement, parties have submitted a modified action plan every five years to address climate change [1]. An action plan contains the policy measures and plans of a country by sector to mitigate GHG emissions. Korea has formulated the "2050 Carbon Neutral Strategy" with the action plan in [2]. In the 2050 Strategy, it is noted that energy efficiency is a significant and effective policy tool for carbon mitigation. The Korean government has plans for the industrial sector to reduce energy consumption by improving energy efficiency.

The industrial sector accounts for most GHG emissions, including indirect emissions from fuel combustion. According to the Intergovernmental Panel on Climate Change [3], industries account for $32 \%$ of global GHG emissions, with $11 \%$ of those indirect emissions. Policymakers need to identify a pathway to decarbonize the industrial sector. However, the industrial sector plays a vital role in economic growth, and to produce value added, it inevitably generates GHG emissions [4]. Drastic decarbonization may be harmful to the national economy [5]. However, the industrial sector has significant potential to mitigate carbon emissions. It will be necessary to utilize various policy measures to achieve industrial decarbonization without economic recession [6]. 
Energy efficiency has been referred to as "the first fuel", which means that energy efficiency can primarily be considered for meeting the increasing energy demand [7]. Improved energy efficiency provides many other benefits for energy transition; the latter makes energy production and usage clean, thus reducing GHG emissions, while the former can contribute to both energy security and GHG mitigation. Improved energy efficiency is not limited by reserves and the international environment, and therefore, it decreases energy import costs and foreign dependency. Improved energy efficiency fills the gap between increased energy demand and decreased supply without reducing the quality of energy service [8]. For consumers, households and enterprises can reduce energy costs, which increases consumer budgets and improves enterprise competitiveness [9].

Electrification has emerged as a fundamental approach toward reducing carbon emissions. European Union (EU) countries have developed long-term strategies to increase their electricity consumption share in the industrial and transportation sectors [10]. Furthermore, electricity can be an energy-saving medium, which makes energy consumption more efficient with power-to-grid, power-to-heat, and sector coupling. Electrification will eventually be environmentally beneficial when the industrial electrification infrastructure is stabilized and combined with the expansion of renewable electricity.

Industrial electricity consumption is expected to increase with the electrification policy. Consequently, electrical systems can be overburdened in cases where the national electricity grid is not adequately constructed [11]. As the global trend demonstrates a significant investment increase in renewable energy, the renewable capacity of each country is expected to increase [12]. However, because of the intermittency of renewable energy, the electricity system needs to be stabilized by several factors, such as baseload generation and energy demand management. In general, baseload generation is sourced from nonclean sources, such as coal and nuclear, which may be phased out. The remaining option is to manage electricity demand through electricity system optimization and demand forecasting. Therefore, industrial electricity consumption that accounts for national electricity consumption needs to be investigated to determine the driving factors.

With a focus on Korea, the aim of this study was to estimate the impacts of electrification and efficiency on industrial electricity consumption. This study contributes to the literature by revising the decomposition equation to suggest a different perspective on electrification and electricity energy efficiency by exploring the electricity consumption data of the industrial sector. Our empirical results indicate that the hidden electrification impact on electricity consumption may hinder the direct cognizance of electricity consumption, thereby leading to a misunderstanding of industrial electricity efficiency. For the last two decades, Korean industrial electricity efficiency has been improved significantly, although it has been shielded by the intensity effect. To identify the determinants of industrial electricity consumption, a decomposition analysis was conducted by utilizing the log mean Divisia index (LMDI) developed by Ang [13]. This method exploits the perfect decomposition demonstrated by both time- and component-reversal invariants.

The remainder of this study is organized as follows: In Section 2, we introduce the existing literature related to decomposition analysis. The data and empirical model adopted in the study are detailed in Section 3. The empirical results and conclusions are presented in Sections 4 and 5, respectively.

\section{Literature Survey}

Several studies have been conducted on the decomposition analyses of the Korean manufacturing industry using the LMDI method. For the empirical analysis, Kim [14] conducts a decomposition analysis using LMDI to investigate the drivers of energy consumption in the Korean manufacturing sector. Consistent with the present study, the author adopts additive and multiplicative LMDI methods. Choi and Oh [15] also focus on the Korean manufacturing industry but attempt to decompose energy intensity. Employing a data-side approach, Park and Kim [16] suggest an insight by comparing decomposition results using primary energy supply and final energy consumption. Jin and Choi [17] apply 
a global value chain to decomposition analysis by combining a world input-output table with an industrial value-added table. The authors suggest a meaningful approach; they consider domestic energy consumption with trade dependency. Kim [18] reviews case studies on the decomposition analysis of Korean energy consumption and makes suggestions using physical output as an intensity indicator rather than monetary output. From the implications of [18], in the most recent study, Lee and Kim [19] attempt to compare the decomposition results in the Korean manufacturing sector between monetary and physical output. They concluded that monetary-based decomposition results may show distorted outcomes based on the evidence that the expansion of the energy-intensive industry is revealed by only physical output-based decomposition.

The decomposition analysis of the Korean manufacturing industry has not been only focused on energy consumption. Oh et al. [20] conducted an LMDI analysis to decompose the carbon emissions of the Korean manufacturing industry. They investigated sectoral trends of carbon emissions, the effects of the main factors of carbon emissions in each sector, and the main drivers of the changes in terms of energy policy and socioeconomic characteristics. Jeong and Kim [21] decomposed GHG emissions in the Korean manufacturing sector using the LMDI method. Their findings provide insights into building a long-term low-carbon economy using the LMDI method. Based on GHG decomposition analysis, Balezentis [22] and Su et al. [23] also contributed to the decomposition literature with empirical analyses on the Lithuanian residential sector and G7 and BRICS countries. Both studies have established that energy intensity plays an important role in carbon mitigation. Especially according to the results of Su et al.'s [23] study, the declining role of energy intensity in GHG emissions has been lowered in developing countries compared to developed countries.

World energy consumption is concentrated in China and accounts for $24 \%$ of the global energy consumption [24]. Consequently, the existing studies on decomposition analysis for domestic energy consumption have been conducted in China. Xu et al. [25] conducted a decomposition analysis of energy consumption in China's cement industry sector. As suggested by Kim [18], Xu et al. [25] adopted the physical output of the cement industry to measure the production effect with precise quantities rather than monetary estimation. Wang et al. [26] suggested using a combined model of the LMDI and the Cobb-Douglas (CD) production function to enhance decomposition analysis with economic theory. In their model, the production effect in the LMDI decomposition can be broken down into capital and labor effects, as suggested by the $\mathrm{CD}$ production function. However, Wang and Feng [27] attempted to reflect the scale effect while investigating the energy consumption of the nonferrous metal industry by decomposing production effects into labor productivity and industry-scale effects. Sun and Liu [28] attempted a new approach by using the national debt factor with a modification of the decomposition equation. Their empirical results indicate that debt-related factors have a positive impact and mostly contribute to China's increased energy consumption.

Decomposition analysis has also been conducted for different countries in the literature. Achour and Belloumi [29] decomposed Tunisian energy consumption by focusing on the transportation sector. They attempted to reflect transport quantity and population effects in the decomposition equation by using annual data from 1985 to 2014. Akyurek [30] investigated the driving factors of manufacturing industry energy consumption in Turkey, similar to Kim [14]. Akyurek's [30] research includes 10 manufacturing industries, whereas Kim [14] decomposed manufacturing energy consumption in nine manufacturing sectors. Bianco [31] focused on the tourism sector in Italy to decompose electricity consumption using seven factors, namely, energy intensity, productivity, turnover, accommodation structure, average hotel dimension, hotel share, and the total number of hospitality structures. These authors have suggested that sector-specific analysis can reflect the characteristics of the sector in the decomposition analysis.

Decomposition analysis has extended the implications by broadening research into cross-country analysis. Fernandez et al. [32] adopted decomposition analysis with three 
decomposition levels to ascertain the determinants of energy consumption in EU-27 countries. The three decomposition levels were classified by country level, region, and energy intensity. The results imply that at each decomposition level, the empirical results show different driving factors for energy consumption. Chen et al. [33] conducted a decomposition analysis on energy consumption, focusing only on the agricultural industry for 89 countries. They attempted to determine the decoupling trend between energy consumption and economic growth based on the evidence of production effects in the decomposition analysis. They found that only 18 countries reached the decoupling stage.

For this literature review, we adopted the LMDI method to investigate domestic energy consumption, attempted to extend the decomposition equation with a production function, and conducted a sectoral analysis. Similarly, the present study extends the decomposition equation, but in a way that differs from previous studies, and investigates the impact of electrification on industrial electricity consumption.

Industrial electricity consumption is expected to be highly affected by the COVID-19 pandemic. According to Gillingham et al. [34], owing to COVID-19, electricity demand has declined by approximately $10 \%$ in the United States. According to other literature, electricity consumption has decreased by $13.49 \%$ in Spain, which is one of the countries that has been most affected by the pandemic [35]. Given that global gross domestic product loss from the COVID-19 pandemic has reached 6.7\% in 2020 [36], the determinants of industrial electricity consumption can show different regimes from ex-ante to ex-post. Accordingly, empirical research on industrial electricity consumption should be undertaken in 2022, when industrial data reflecting the impact of COVID-19 will be published.

\section{Materials and Methods}

\subsection{Data Description}

To construct the decomposition equation, empirical data were collected on electricity consumption, the share of electricity in final energy consumption (electrification), and the value added. We analyzed the impact of industrial electrification on electricity consumption, and the final energy consumption in the electrification variable indicates fuel usage only. This empirical dataset incorporates 11 industrial sectors for the period from 2000 to 2018. Electricity consumption and the final energy consumption were obtained from the energy balance published by the Korea Energy Economics Institute [37]. The value-added data for each industry were collected via the Korean Statistical Information Service [38]. The empirical data were collected from authorized statistics in Korea. However, our empirical data of electricity consumption cannot cover the industry's own generation and consumption, such as the dispersed generation of photovoltaics and wind power. Although this can function as the uncertainty of our empirical analysis, the share of it in industrial electricity consumption is small.

Figure 1 indicates Korea's industrial electricity consumption from 2000 to 2018, which has increased by an annual average rate of $4.3 \%$. This value is higher than the industrial value-added growth (annual average of $4.1 \%$ ) and energy consumption increase (annual average of $3.3 \%$ ). The share of industrial to national electricity consumption decreased from 2000 to 2009 , and the share rebounded to $53.9 \%$ as of 2018 .

Table 1 shows the electricity consumption and value added by the industrial sector. The electricity consumption of each sector increased from 2010 to 2018, except for the textile and leather industries. The industries with the highest increments were the fabricated metal and agriculture/forestry/fishing sectors, which show a $6.7 \%$ annual average growth rate, followed by the nonmetallic and petrochemical sectors. Conversely, electricity consumption in the textile and leather sectors decreased by an annual average of $2.0 \%$. The far right-hand column in Table 1 presents the share of electricity consumption in the fuel consumption of a sector. That is, the electricity consumption share denotes the electrification rate of the sector. The electricity consumption share in the industrial sector increased by $1.7 \%$ of the annual average growth rate, particularly for the agriculture/forestry/fishing sector (annual average of $9.2 \%$ ). As of 2018, for the industrial electricity consumption share by sector, 
the fabricated metal sector (37.6\%) accounted for the most, followed by the petrochemical sector $(22.0 \%)$. This implies that the industrial sector in Korea is highly concentrated in energy-intensive industries.

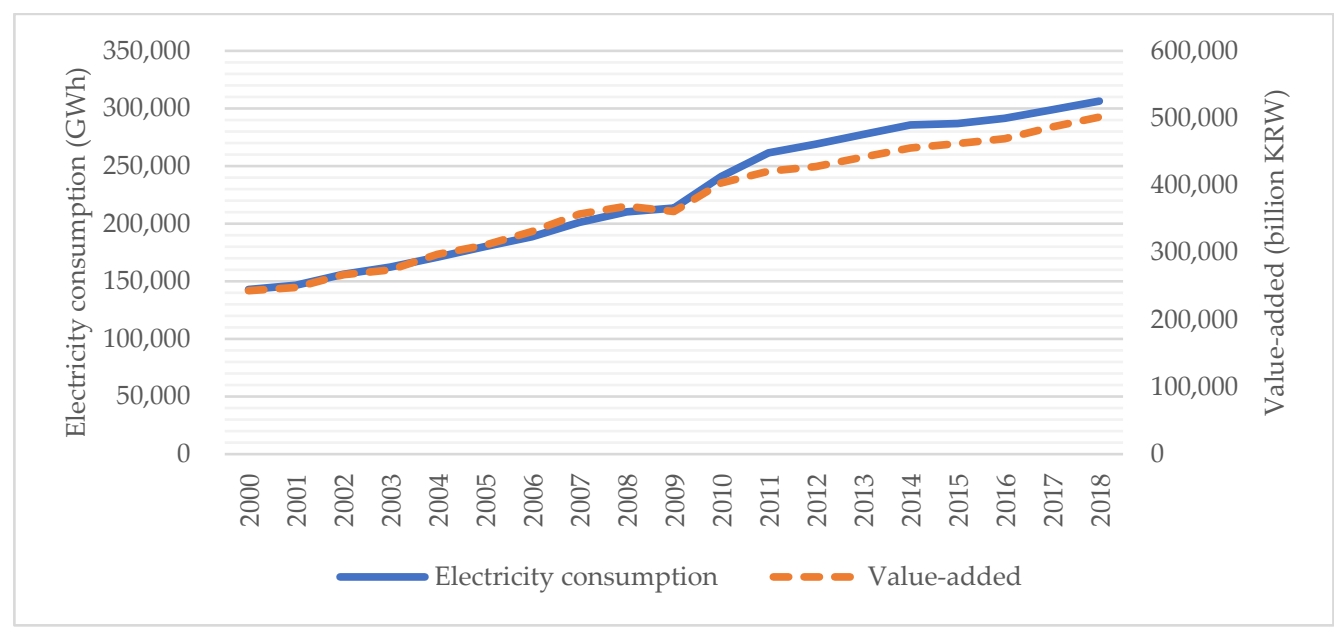

Figure 1. Electricity consumption and value added of the Korean industrial sector (2000-2018).

Table 1. Electricity consumption, value added, and shares in 2000 and 2018.

\begin{tabular}{|c|c|c|c|c|c|c|}
\hline \multirow{2}{*}{ Subsector } & \multicolumn{2}{|c|}{$\begin{array}{c}\text { Electricity } \\
\text { Consumption (GWh) }\end{array}$} & \multicolumn{2}{|c|}{$\begin{array}{l}\text { Value-Added } \\
\text { (Billion KRW) }\end{array}$} & \multicolumn{2}{|c|}{$\begin{array}{c}\text { Electricity } \\
\text { Consumption Share * }(\%)\end{array}$} \\
\hline & 2000 & 2018 & 2000 & 2018 & 2000 & 2018 \\
\hline Food and tobacco & 6149 & 11,950 & 16,094 & 21,388 & 33.1 & 53.8 \\
\hline Textile and leather & 15,497 & 10,835 & 15,669 & 15,066 & 39.1 & 75.3 \\
\hline Wood and pulp & 9980 & 11,512 & 10,591 & 13,679 & 38.6 & 73.8 \\
\hline Petrochemical & 26,899 & 62,316 & 38,431 & 76,428 & 37.3 & 36.5 \\
\hline Non-metallic & 8981 & 12,147 & 8078 & 13,888 & 13.9 & 24.4 \\
\hline Basic metal & 19,997 & 34,852 & 20,223 & 28,026 & 10.4 & 10.4 \\
\hline Non-ferrous metal & 3755 & 10,018 & 19,219 & 34,440 & 52.4 & 52.3 \\
\hline Fabricated metal & 32,997 & 106,666 & 78,474 & 253,414 & 55.6 & 80.3 \\
\hline Other manufacturing & 1697 & 4803 & 5876 & 10,763 & 2.4 & 15.3 \\
\hline Agriculture/forestry/fishing & 5306 & 17,126 & 27,070 & 32,540 & 11.2 & 54.4 \\
\hline Mining and quarrying & 1003 & 1478 & 3370 & 2031 & 60.6 & 70.0 \\
\hline
\end{tabular}

* Note: Electricity consumption share shows the electrification rate of the sector.

\subsection{LMDI Model}

Index decomposition analysis (IDA) has been widely developed and applied in various ways. Two representative methods of IDA use the refined Laspeyres index and LMDI proposed by Sun [39] and Ang [13], respectively. These two methods satisfy four conditions of ideal IDA, namely, completeness, time reversal, factor reversal, and zero-value robustness [40]. The completeness and robustness of the zero value mean that decomposition with no residual and decomposition are secured under the existence of zero value, respectively. Time- and factor-reversal indicate that the decomposition result does not depend on the order of time and factors.

Decomposition analysis based on a time series is classified into fixed and rolling base years. The fixed base year shows a long-term trend compared to the rolling base year, which focuses on a single time shift. Another IDA classification is based on the calculation method of additive and multiplicative decomposition. According to the calculation method, the fixed base year decomposition results can be derived by the cumulative addition or multiplication of the rolling base year decomposition. There is no preference for additive or multiplicative decomposition [41]. Both methods were used in this study. 
Here, the standard LMDI suggested by Ang [42,43] decomposed electricity consumption into three effects, namely, production, structure, and intensity effects, because the LMDI method adopts a log transformation that complicates decomposition when raw data contain zero values. However, Ang and Liu $[44,45]$ suggested that the zero value in the data is handled by a small value strategy that substitutes a zero value with a small value such as $10^{-20}$. The production effect indicates that the energy consumption increases to produce value added in the industrial sector, while the structure and intensity effects imply the influence of weight change in the industrial value-added structure and energy intensity on energy consumption, respectively.

The IDA-derived intensity effect generally represents the impact of efficiency on electricity consumption because IDA removes the impacts from production scale and industrial structure effects. Industrial electricity consumption in year $t$ can be decomposed into four factors, as expressed in Equation (1). The four factors can be the determinants of electricity consumption according to the chain rule. The gap $(\Delta E)$ between a base year and a subject year can be expressed by the changes in three factors (Equation (2)).

$$
\begin{gathered}
E_{t}=\sum_{i}\left(Y_{t} \times \frac{Y_{i t}}{Y_{t}} \times \frac{F_{i t}}{Y_{i t}} \times \frac{E_{i t}}{F_{i t}}\right), \\
\Delta E=\Delta E_{Y}+\Delta E_{S}+\Delta E_{\text {eff }}+\Delta E_{\text {elec }}
\end{gathered}
$$

where $E$ and $Y$ represent the industrial electricity consumption and value added, respectively. In Equation (2), $\Delta E_{Y}, \Delta E_{S}, \Delta E_{\text {eff }}$ and $\Delta E_{\text {elec }}$ are production, structure, fuel efficiency, and electrification effect factors, respectively. The four factors can be computed using Equations (3)-(6):

$$
\begin{gathered}
\Delta E_{Y}=\sum_{i}\left(\frac{E_{i t}-E_{i t-1}}{\ln \left(E_{i t} / E_{i t-1}\right)}\right) \times \ln \left(\frac{Y_{t}}{Y_{t-1}}\right), \\
\Delta E_{S}=\sum_{i}\left(\frac{E_{i t}-E_{i t-1}}{\ln \left(E_{i t} / E_{i t-1}\right)}\right) \times \ln \left(\frac{S_{i t}}{S_{i t-1}}\right), \\
\Delta E_{\text {eff }}=\sum_{i}\left(\frac{E_{i t}-E_{i t-1}}{\ln \left(E_{i t} / E_{i t-1}\right)}\right) \times \ln \left(\frac{F_{i t} / Y_{i t}}{F_{i t-1} / Y_{i t-1}}\right), \\
\Delta E_{\text {elec }}=\sum_{i}\left(\frac{E_{i t}-E_{i t-1}}{\ln \left(E_{i t} / E_{i t-1}\right)}\right) \times \ln \left(\frac{E_{i t} / F_{i t}}{E_{i t-1} / F_{i t-1}}\right),
\end{gathered}
$$

where $F$ indicates industrial fuel consumption, that is, the share of electricity in industrial fuel consumption, while $\left(E_{i t} / F_{i t}\right)$ represents the electrification of an industrial sector.

In Equations (3)-(6), the first term on the right represents the Divisia index, which was utilized as the weight for LMDI. Industrial structure $(S)$ indicates the share of a specific industry to the entire industry in terms of value added $\left(S_{i t}=Y_{i t} / Y_{t}\right)$. The main goal of the study was to reveal the electrification effect on industrial electricity consumption by decomposing the intensity effect into electrification and the fuel efficiency effect. The scheme of LMDI in the study is presented in Figure 2. Using the simple chain rule, the electricity intensity $\left(I=E_{i t} / Y_{i t}\right)$ can be decomposed as follows:

$$
\begin{gathered}
\frac{E_{i t}}{Y_{i t}}=\frac{F_{i t}}{Y_{i t}} \times \frac{E_{i t}}{F_{i t}}, \\
\Delta E_{I}=\sum_{i}\left(\frac{E_{i t}-E_{i t-1}}{\ln \left(E_{i t} / E_{i t-1}\right)}\right) \times \ln \left(\frac{I_{i t}}{I_{i t-1}}\right) .
\end{gathered}
$$

where the intensity effect $\left(\Delta E_{I}\right)$ in the original LMDI equation can be calculated by Equation (8) [42]. 


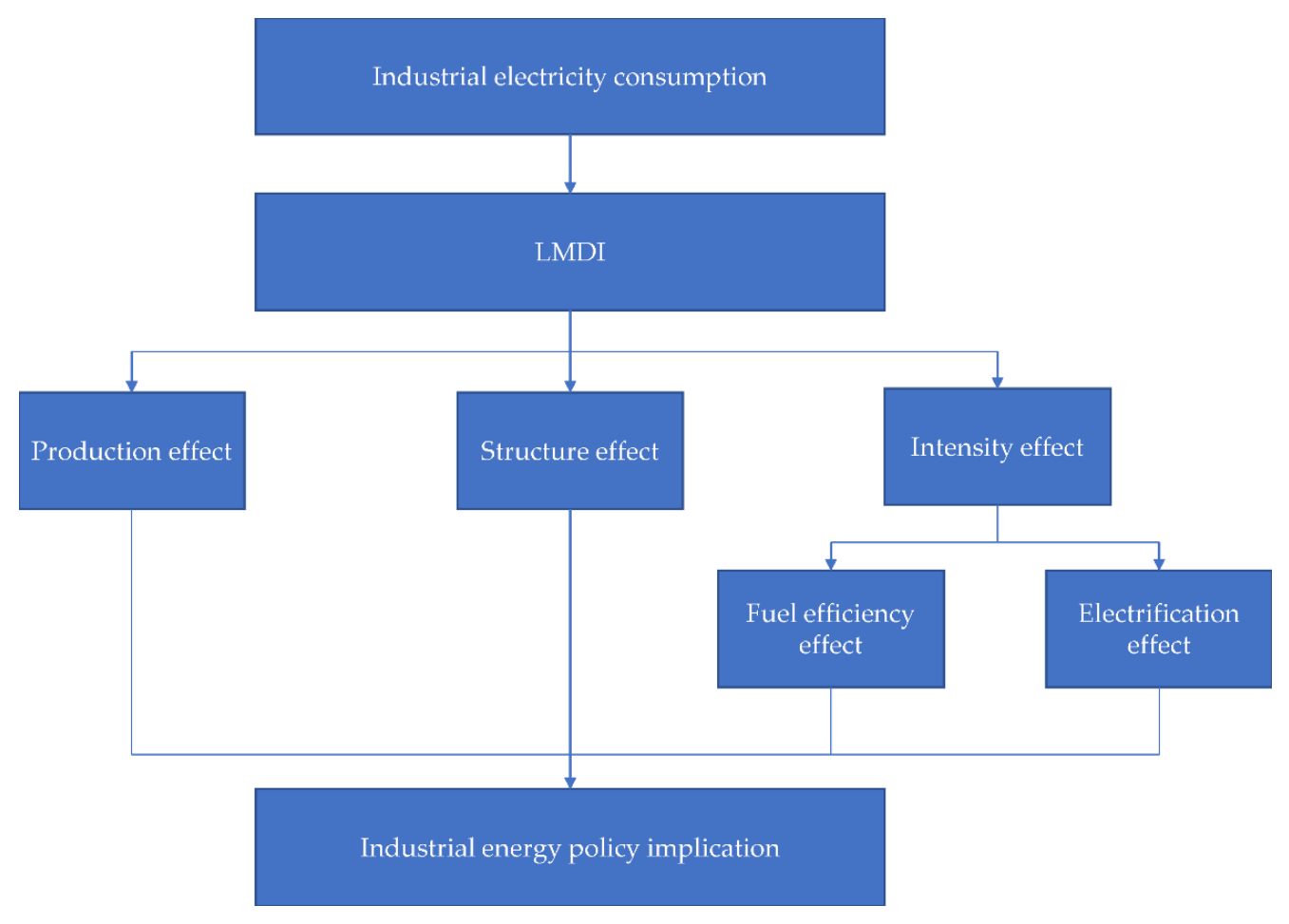

Figure 2. LMDI scheme in the study.

Our LMDI equation shows that energy consumption can be decomposed into four factors: production, structure, electrification, and efficiency effects. Production effect $\left(\Delta E_{Y}\right)$ represents the impact of economic growth calculated by growth in value-added on energy consumption in the industrial sectors. The structure effect $\left(\Delta E_{S}\right)$ measures how much the industrial value-added structure affects energy consumption. If the structure effect has reduced industrial energy consumption, it means that the economic structure gives weight to the sectors with low-energy consumption and high value added. The intensity effect $\left(\Delta E_{I}\right)$ investigates the intensity change by sector on industrial energy consumption, which is decomposed into electrification $\left(\Delta E_{\text {elec }}\right)$ and efficiency effect $\left(\Delta E_{e f f}\right)$. Decreasing the impact of the intensity effect on energy consumption indicates that the industrial energy efficiency improved.

The efficiency effect $\left(\Delta E_{e f f}\right)$ shows the impact of fuel usage to produce units of value added, which is translated into fuel efficiency, on industrial electricity consumption. The negative efficiency effect denotes fuel efficiency improvement in the industrial sector. The electrification effect $\left(\Delta E_{\text {elec }}\right)$ indicates how the share of electricity in fuel usage affects electricity consumption in the industrial sector. That is, the electrification effect isolates the impact of electrification on electricity consumption from the intensity effect that may induce confusion. For instance, if electrification has proceeded quickly, the intensity effect is derived as if the industrial efficiency deteriorates despite improved energy efficiency.

Multiplicative decomposition does not significantly differ from additive decomposition [46]. While the change between the base and target years is expressed by delta $\left(\Delta E=E_{t}-E_{0}\right)$ in additive decomposition, multiplicative decomposition uses the growth rate $\left(D_{\text {tot }}=E_{t} / E_{0}=D_{Y} D_{S} D_{\text {eff }} D_{\text {elec }}\right)$. The production, structure, fuel efficiency, and electrification effects by multiplicative decomposition can be expressed as given in the following equations [47]:

$$
D_{Y}=\exp \left(\sum_{i} \frac{\left(\frac{E_{i t}-E_{i t-1}}{\ln \left(E_{i t} / E_{i t-1}\right)}\right)}{\left(\frac{E_{t}-E_{t-1}}{\ln \left(E_{t} / E_{t-1}\right)}\right)} \times \ln \left(\frac{Y_{t}}{Y_{t-1}}\right)\right),
$$




$$
\begin{gathered}
D_{S}=\exp \left(\sum_{i} \frac{\left(\frac{E_{i t}-E_{i t-1}}{\ln \left(E_{i t} / E_{i t-1}\right)}\right)}{\left(\frac{E_{t}-E_{t-1}}{\ln \left(E_{t} / E_{t-1}\right)}\right)} \times \ln \left(\frac{S_{t}}{S_{t-1}}\right)\right), \\
D_{\text {eff }}=\exp \left(\sum_{i} \frac{\left(\frac{E_{i t}-E_{i t-1}}{\ln \left(E_{i t} / E_{i t-1}\right)}\right)}{\left.\frac{E_{t}-E_{t-1}}{\ln \left(E_{t} / E_{t-1}\right)}\right)} \times \ln \left(\frac{F_{i t} / Y_{i t}}{F_{i t-1} / Y_{i t-1}}\right)\right), \\
D_{\text {elec }}=\exp \left(\sum_{i} \frac{\left(\frac{E_{i t}-E_{i t-1}}{\ln \left(E_{i t} / E_{i t-1}\right)}\right)}{\left(\frac{E_{t}-E_{t-1}}{\ln \left(E_{t} / E_{t-1}\right)}\right)} \times \ln \left(\frac{E_{i t} / F_{i t}}{E_{i t-1} / F_{i t-1}}\right)\right),
\end{gathered}
$$

where $D_{Y}, D_{S}, D_{e f f}$ and $D_{\text {elec }}$ denote production effect, structure, fuel efficiency, and electrification effect from multiplicative LMDI, respectively, in multiplicative decomposition. The difference between additive and multiplicative decompositions is in the Divisia index. While additive decomposition uses the weight factor presented in $\frac{E_{i t}-E_{i t-1}}{\ln \left(E_{i t} / E_{i t-1}\right)}$, multiplicative decomposition adopts $\frac{\left(\frac{E_{i t}-E_{i t-1}}{\ln \left(E_{i t} / E_{i t-1}\right)}\right)}{\left(\frac{E_{t}-E_{t-1}}{\ln \left(E_{t} / E_{t-1}\right)}\right)}$.

\section{Empirical Results}

\subsection{Aggregate Industrial Electricity Decomposition}

This study focused on the long-term trend of electricity consumption changes in the Korean industrial sector from 2000 to 2018. The determinants were investigated based on the IDA method. Fixed and rolling base year methods were both adopted to determine the drivers of Korean industrial electricity consumption, particularly in the measurement of electrification and efficiency effects. The production, structure, intensity, electrification, and efficiency effects for the entire industry according to the cumulative change from 2000 to 2018 are depicted in Figure 3.

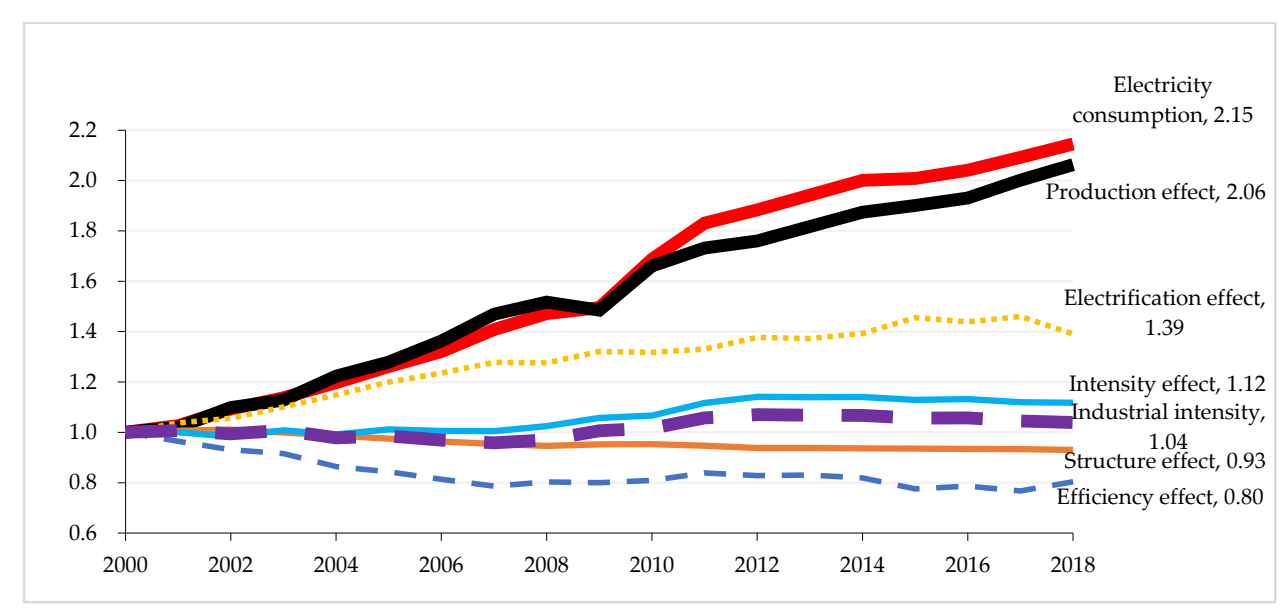

Figure 3. Aggregate electricity consumption LMDI results (fixed base year, multiplicative).

The decomposition analysis results have several implications. While the industrial structure reduced industrial electricity consumption, the intensity effect indicates that electricity intensity continues to be an increasing factor for electricity consumption. The decomposition results for electricity intensity indicate that although electricity efficiency improved, the electrification effect largely affected electricity intensity positively. From 2000 to 2018, the growth rate of industrial electricity consumption was lower than the production effect, which was caused by aggregate industrial intensity deterioration. Overall, production and electrification effects increased industrial electricity consumption, whereas structure and efficiency effects decreased it. 
A rolling base year approach was applied to the additive decomposition method for aggregate industrial electricity consumption (Table 2). In 2000 and 2018, the industrial electricity consumption rates were $132,260 \mathrm{GWh}$ and $295,820 \mathrm{GWh}$, respectively. This demonstrates that industrial electricity consumption increased by $163,560 \mathrm{GWh}$, with an annual average growth rate of $4.1 \%$ from 2000 to 2018 . The last row in Table 2 presents the fixed base year results for the target year 2018. The cumulation of the rolling base year approach shows the results of decomposition based on pairwise year changes.

Table 2. Additive LMDI results with a rolling base year.

\begin{tabular}{ccccccc}
\hline \multirow{2}{*}{ Year } & Growth & Production Effect & Structure Effect & Intensity Effect & \multicolumn{2}{c}{ Intensity Effect } \\
\cline { 5 - 7 } & & & & Electrification Effect & Efficiency Effect \\
\hline 2001 & 3814 & 2820 & 964 & 30 & 5322 & -5292 \\
2002 & 9355 & 11,253 & 680 & -2578 & 2666 & -5244 \\
2003 & 6408 & 4270 & -1846 & 3983 & 6623 & -2640 \\
2004 & 8586 & 13,494 & -2227 & -2680 & 7102 & -9783 \\
2005 & 9154 & 7798 & -2051 & 3406 & 7643 & -4237 \\
2006 & 8476 & 11,692 & -2142 & -1073 & 5414 & -6487 \\
2007 & 12,518 & 14,666 & -1929 & -219 & 6576 & -6796 \\
2008 & 9048 & 6618 & -1651 & 4082 & -318 & 4399 \\
2009 & 3363 & -4545 & 1295 & 6614 & -533 & -734 \\
2010 & 27,462 & 25,305 & 232 & 1924 & 2478 & 2457 \\
2011 & 20,556 & 10,617 & -1645 & 11,584 & 9015 & -3106 \\
2012 & 7486 & 4286 & -2506 & 5706 & -817 & -3308 \\
2013 & 8322 & 8761 & -183 & -257 & 3923 & -360 \\
2014 & 8399 & 8631 & -365 & -133 & 12,758 & $-15,591$ \\
2015 & 1097 & 4098 & -168 & -2833 & -3298 & 4000 \\
2016 & 4690 & 4456 & -288 & 702 & -748 \\
2017 & 7231 & 10,678 & -1041 & -3158 & $-14,730$ & 14,182 \\
2018 & 7597 & 9186 & $-15,340$ & 24,817 & 61,460 & $-36,643$ \\
Total & 163,560 & 154,084 & & &
\end{tabular}

The cumulative production $(+154,084 \mathrm{GWh})$ and intensity $(+24,817 \mathrm{GWh})$ effects increased industrial electricity consumption, whereas the structure effect $(-15,340 \mathrm{GWh})$ constantly functioned as a decreasing factor. Among the intensity effects, electrification and efficiency effects show a reversed impact on industrial electricity consumption. The Korean industrial sector has reduced electricity consumption by improving electricity efficiency. Electricity consumption increased by $61,460 \mathrm{GWh}$ because of electrification. In contrast, electricity efficiency reduced consumption by $36,643 \mathrm{GWh}$. These results imply that despite all the efficiency improvement and industrial structure redistribution efforts, industrial electricity consumption has constantly increased.

The production effect has continuously contributed to an increase in industrial electricity consumption, except in 2009, owing to the financial crisis. Therefore, while electricity consumption constantly increased from 2000 to 2018, value added from industrial sectors reduced markedly. The structure effect decreased electricity consumption. During the analysis period, the structure effect increased electricity consumption in 2001, 2002, and 2010. Until the early 2000s, the Korean economy was highly dependent on the petrochemical sector, which increased the structure effect.

In most years of the analysis period, the intensity effect increased electricity consumption, which suggests that electricity consumption, compared to the production of value added, has increased. Completing the empirical analysis within three-factor decomposition may imply that the electricity consumption efficiency in Korea has deteriorated. However, the electricity intensity effect may be overestimated by the electrification policy, which substitutes fuels used in industrial sectors. Consequently, most of the electricity intensity effect was derived from the electrification effect $(61,460 \mathrm{GWh})$ rather than a decrease in efficiency. Furthermore, it has been found that industrial electricity efficiency has constantly decreased 
industrial electricity consumption. These empirical results are consistent with the previous study on the electrification of the Korean manufacturing sector, which determined that the industrial electrification effect is comparable to the production effect [48]. Compared to the results of the study conducting decomposition analysis on final energy decomposition, where the consistent results of the structure effect were derived as a decreasing factor of consumption, the intensity effect was different [19]. This implies that the other form of final energy, heat consumption, increased in industrial sectors.

\subsection{Electricity Consumption Decomposition by Sector}

It has been established that most aggregate electricity consumption is driven by valueadded production. An important finding is that electrification has increased consumption rather than decreasing efficiency. To specify the policy implications by sector, decomposition analysis should be applied to each industrial sector. Sectors that have shown high electrification and induced an increase in electricity consumption can be determined from this analysis. Furthermore, it can prioritize industrial sectors to address demand management by sector. In the case of sector analysis, the value-added structure cannot be applied. Therefore, electricity consumption in a sector is divided into three components, namely, production, electrification, and efficiency effects.

In Korea, the food and tobacco industry accounted for $4.2 \%$ of the industrial electricity consumption as of 2018. Figure A1 depicts the multiplicative decomposition results for a fixed base year. Over the last two decades, electricity consumption in the food and tobacco sector has increased more than value-added growth (Figure A1). The decomposition results indicate that an increase in electricity consumption was mostly induced by production and electrification, despite efficiency improvement. In particular, electrification was the primary contributor to the increase in electricity consumption rather than the production effect, which demonstrates that electrification has been rapidly conducted in the sector. Electrification in the food and tobacco sector increased by $20.7 \%$, from $33.1 \%$ in 2000 to $53.8 \%$ in 2018 . The efficiency effect derived was 0.90 , implying that electricity efficiency improved by approximately $10 \%$.

Electricity consumption in the textile and leather sectors has a $3.8 \%$ share of the industrial electricity consumption. Unlike the other sectors, electricity consumption in the textile and leather sectors decreased. The decline in electricity consumption was more rapid than the value-added production decline (Figure A2). Consistent with the food and tobacco sector, electrification mostly contributed to an increase in electricity consumption. However, production and efficiency negatively affected electricity consumption. The intensity effect derived was 0.73 , decreasing electricity consumption in the textile and leather sectors. Among the intensity effects, electrification rapidly increased electricity consumption, and efficiency improvement in the sector has been sufficient to offset the increment by the electrification effect.

The wood and pulp industry accounts for a similar share of industrial electricity consumption. Figure A3 illustrates the decomposition results of electricity consumption in the wood and pulp sector. Electricity consumption within the sector shows a lower growth rate than value added through intensity improvement efforts. Electricity consumption in the sector increased by 15\%, which ensued from the combination of production (increase 29\%) and intensity (decrease 11\%) effects. This is consistent with the textile and leather sectors, although electrification significantly contributed to an increase in electricity consumption, mitigated by an improvement in fuel usage.

The petrochemical industry is one of the most energy-intensive industries in Korea, accounting for $22.0 \%$ of the industrial electricity consumption as of 2018 . The decomposition presents results (Figure A4) that differ from those of the other sectors. Electricity consumption more than doubled throughout the analysis period. The rapid growth rate was mostly induced by the production effect combined with the deteriorated intensity effect. Electrification in the petrochemical sector served to reduce electricity consumption 
by decreasing electricity consumption as a fuel. An efficiency decrease induced electricity consumption.

The electricity consumption decomposition results for the nonmetallic sector, which accounts for $4.3 \%$ as of 2018, are presented in Figure A5. The intensity and efficiency effects decreased electricity consumption, whereas electrification and production effects had a significant positive impact on electricity consumption. Electrification had a greater impact than value-added production. Electrification accounted for $24.4 \%$ in 2018 , increasing by $10.5 \%$ from $2000(13.9 \%)$. This resulted in a large amount of electricity consumption even though electricity efficiency significantly improved.

Figure A6 shows the decomposition results of electricity consumption in the basic metal sector. This sector includes the iron and steel industry, which is one of the foundations of the Korean economy. Electricity consumption in the basic metal sector increased by an annual average of $3.1 \%$, which was more rapid than the value added growth. Electrification had no meaningful contribution to electricity consumption; however, production and efficiency effects caused an increase in electricity consumption. Unlike the other sectors, electricity efficiency was exacerbated in the basic metal industry, requiring more fuel input to the basic metal sector.

The nonferrous metal sector was the most affected by the financial crisis of 2008 . The electricity consumption decomposition results (Figure A7) show that in 2008, electricity consumption declined, owing to the intensity effect. This implies that value added from the sector was produced without significant loss, compared to the decline in electricity consumption. However, during the 2018 recession, electricity consumption in the sector increased by $167 \%$. Similar to the basic metal sector, electrification had no significant impact on electricity consumption. Efficiency was exacerbated, which positively affected electricity consumption.

The fabricated metal sector is also a sector that is crucial to the Korean economy, and value-added production and electricity consumption are the highest. As of 2018, the fabricated metal sector accounted for $37.6 \%$ and $50.5 \%$ of industrial electricity consumption and value-added production, respectively. Figure A8 illustrates the decomposition results for the fabricated metal sector. Throughout the analysis period, electricity consumption in the fabricated metal sector was coupled with the production activity of the sector. This was induced by stagnant electricity intensity in the sector. This sector can be an ideal case for the other sectors because the intensity effect remained stationary, although the decomposed factor, electrification, increased electricity consumption. This implies that electrification was conducted throughout the period, and efficiency improvement offset the increment from electrification that managed electricity consumption in the sector.

The agriculture/forestry/fishing sector accounts for $6.0 \%$ and $6.5 \%$ of industrial electricity consumption and value added, respectively. In addition to the fabricated metal sector, this sector increased industrial electricity consumption. The intensity effect was 2.69, (Figure A9), which caused a significant increase in electricity consumption compared with the relatively small increase in the production effect (1.20). The decomposition results of the intensity effect indicate that electrification in the agriculture/forestry/fishing sector progressed rapidly, whereas improved electricity efficiency decreased electricity consumption. To manage the electricity load, the electrification rate in this sector needs to be decelerated.

The mining and quarrying sector accounts for a large amount of industrial electricity consumption compared to value-added production. This sector is the only one wherein the production effect had a negative impact on electricity consumption (Figure A10). Efficiency and electrification effects, that is, the intensity effect, increased electricity consumption, whereas the production effect decreased it. Electrification increased slightly. Electricity consumption in the sector was less than that of the other sectors, and therefore, the electricity policy on the sector had a small impact. Korea is a representative resource-poor country, and consequently, industry downscaling is inevitable. Efficiency aggravation was induced by a reduction in value-added production. 
The LMDI has been applied in many studies to investigate the determinants of electricity consumption. In the present study, by decomposing the intensity effect into electrification and efficiency effects using the share of electricity in fuel usage by sector, we identified electrification-induced industrial electricity consumption that may differ by sector. In most sectors, electricity consumption has been managed by improved efficiency, although electrification has mostly caused increased electricity consumption. Sectors with highly improved efficiencies need to focus on the decarbonization of industrial processes, whereas sectors that have failed to improve efficiency need incentives and regulations to increase their efficiency.

\section{Conclusion and Policy Implications}

In this study, we analyzed the annual trends in Korean industrial electricity consumption. We utilized the electricity consumption and value-added dataset of 11 sectors in the Korean industry from 2000 to 2018. The LMDI decomposition analysis was conducted to determine the drivers of industrial electricity consumption in aggregate and by sector. From the traditional three-factor decomposition, we extended the decomposition equation into four factors. The intensity effect was decomposed into electrification and efficiency effects to investigate the impact of electrification on electricity consumption by sector.

Our empirical findings demonstrate that the intensity effect in the decomposition analysis of electricity consumption may underestimate efficiency improvement by not considering electrification. Because of the electrification policy, the substitution of other fuels with electricity will facilitate an increase in electricity consumption, and it needs to be separated from the intensity effect. Our decomposition results show that electrification has a major impact by increasing industrial electricity consumption, although the efficiency effect has constantly reduced electricity consumption.

The empirical analysis by sector provides a different perspective. In some sectors, electrification is the most powerful factor affecting electricity consumption (food and tobacco, textile and leather, wood and pulp, non-metallic, and agriculture/forestry/fishing sectors). In particular, fuel substitution with electricity mostly occurred in the agriculture/forestry/fishing sectors. In all sectors, except for mining and quarrying, the efficiency effect reduced industrial electricity consumption. This implies that the policy for industrial electricity efficiency improvement has worked effectively. We revealed the fabricated metal sector to be an ideal case of electrification and efficiency improvement. In this sector, fuel switching has been constantly conducted, and electricity efficiency has simultaneously improved. The substitution of fuel with electrification appears inevitable, and industrial energy efficiency has successfully managed electricity consumption. The industrial sector should make an effort to generate clean electricity and extend electricity load facilities to meet the electricity demand from electrification.

To effectively manage power energy efficiency in the industrial sector, it is necessary to identify the priorities for improving industrial power efficiency by comprehensively considering the power consumption ratio, power conversion ratio, and electricity use efficiency by industry. As of 2018, the power consumption of the industrial sector in Korea was found to be largely in the order of assembly metal, petrochemical, and primary metal industries, with these accounting for $72 \%$ of the total power consumption in the industrial sector. The rate of electrification in the industrial sector increased from $22 \%$ in 2000 to $30 \%$ in 2017, and the proportion of electrification in the order of assembly metal, textile and leather, wood printing, and mining was high, followed by power efficiency, mining, and nonferrous metals. It was found that improving efficiency is necessary, in the order of the primary metals, petrochemicals, and food and tobacco industries. Summarily, it is evident that improving power efficiency is necessary in the assembling metal, petrochemical, and primary metal industries, which is the case in industries with a high proportion of electricity use.

Electrification is an essential pathway toward carbon neutrality. In the transportation sector, fossil fuels are still consumed by large vehicles. The transportation sector also needs to be electrified with electric and hydrogen vehicles. However, electrification will make 
meaningful contributions to carbon neutrality only when clean electricity generation is involved. Although renewable energy expansion will enhance electrification, electricity grids and systems still need to be stabilized. To bridge the energy transition, we still have to develop unused energy and other efficient energy sources.

The implication above suggests several policy tools for energy policymakers. Electrification in industrial sectors still needs to be propelled, and the R\&D for electricity system stabilization and the transition policy should be developed together. Recently, the Korean government prepared for the transformation of the economy toward a hydrogen-based economy. The energy transition of hydrogen is desirable in that it makes the sector coupling possible, which mitigates the overburdening of the electrical system and lowers carbon emissions simultaneously. In addition, for Korea, electricity market liberalization is an especially top priority policy for vitalizing regional electricity transactions.

Although this study provides fresh insight into the literature related to industrial energy, it has several limits. First, industrial sectors in this study include the mining and manufacturing sectors. The transport sector needs to be analyzed since electric vehicles would play a crucial role in carbon mitigation. However, the electrification of the transport sector has not been statistically formulated well. Second, our analysis relied on topdown statistics, while a bottom-up approach would be important for realizing policy implications, especially efficiency policies. Future research can be pursued as follows. For the decomposition of industrial electricity consumption, production technology factors can be considered, such as distance functions. In addition, recently, sectoral capital and labor data became retrievable. A study utilizing production function combined with decomposition analysis is recommended.

Author Contributions: Conceptualization, J.P. and S.L.; methodology, S.L. and T.J.; software, T.J.; validation, T.J.; formal analysis, S.L.; investigation, J.P.; resources, J.P.; data curation, S.L.; writingoriginal draft preparation, T.J.; writing — review and editing, T.J. and J.P.; visualization, T.J.; supervision, J.P.; project administration, J.W.; funding acquisition, J.W. All authors have read and agreed to the published version of the manuscript.

Funding: This research received no external funding.

Institutional Review Board Statement: Not applicable.

Informed Consent Statement: Not applicable.

Data Availability Statement: Data sharing not applicable.

Conflicts of Interest: The authors declare no conflict of interest.

\section{Appendix A}

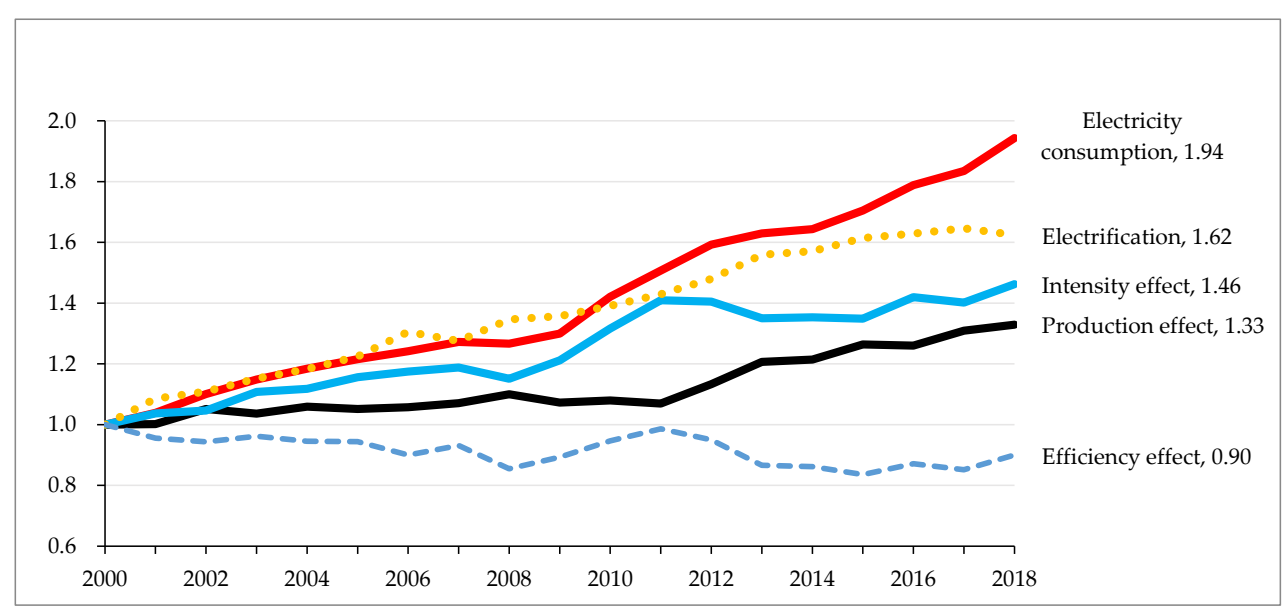

Figure A1. Food and tobacco electricity consumption LMDI results (fixed base year, multiplicative). 


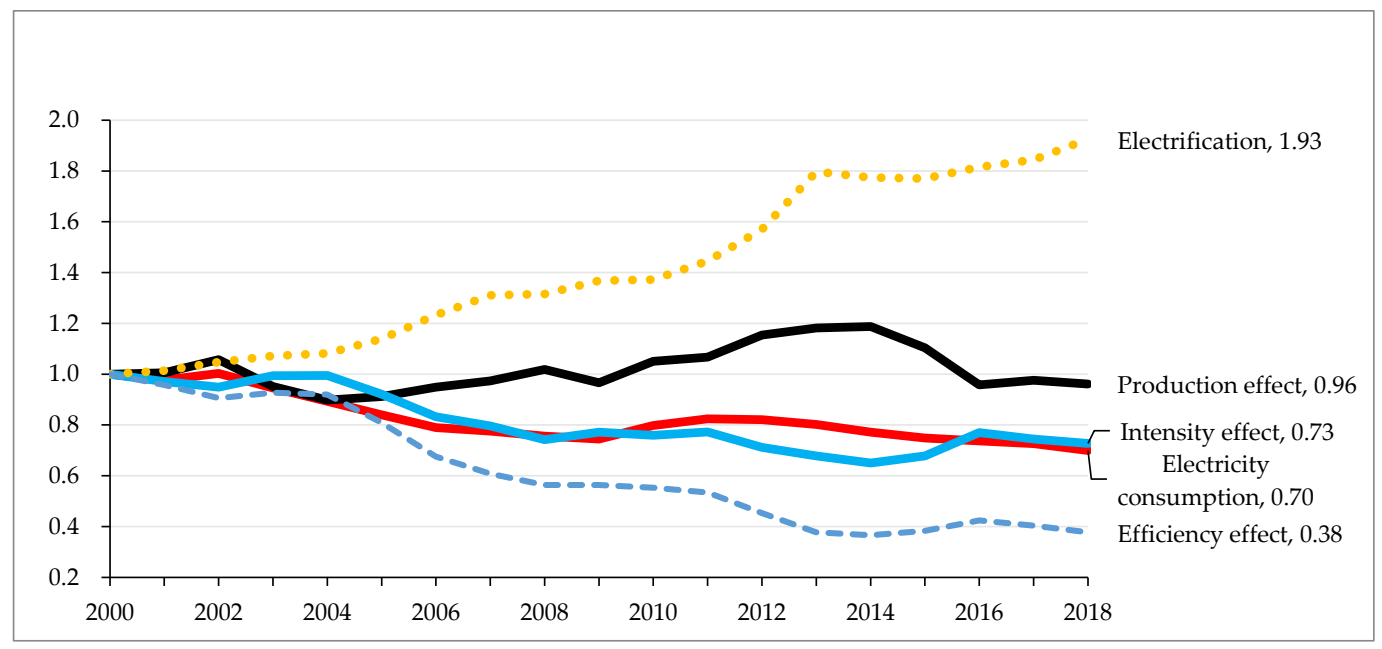

Figure A2. Textile and leather electricity consumption LMDI results (fixed base year, multiplicative).

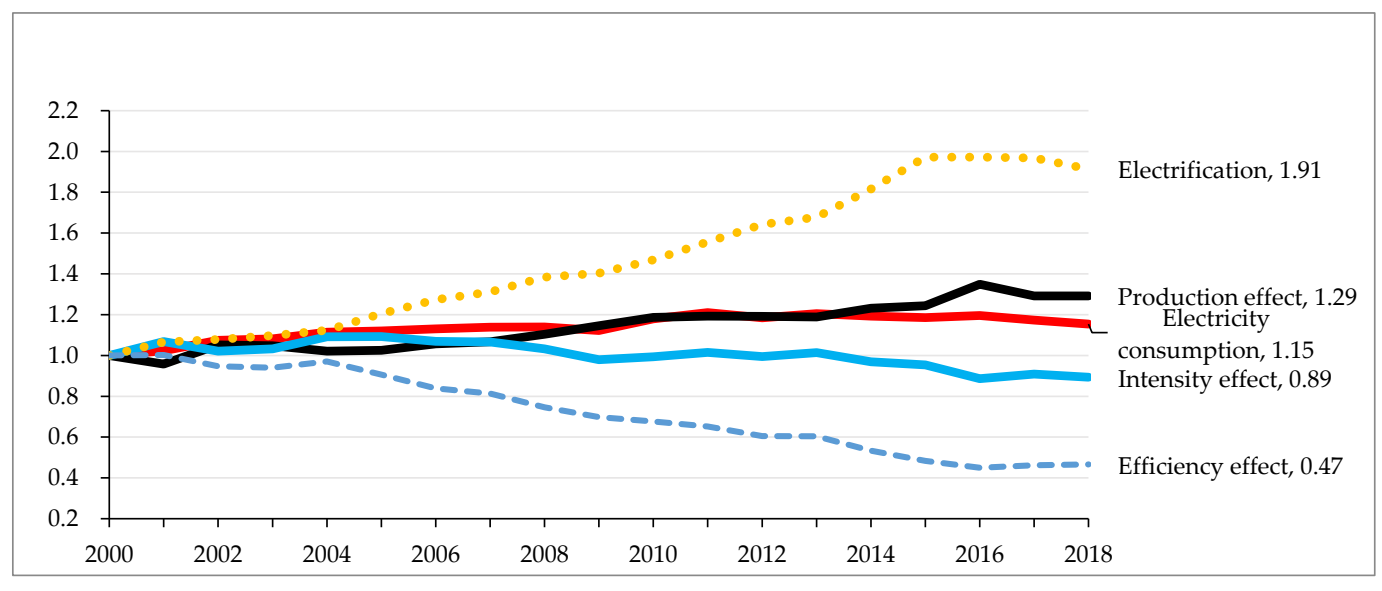

Figure A3. Wood and pulp electricity consumption LMDI results (fixed base year, multiplicative).

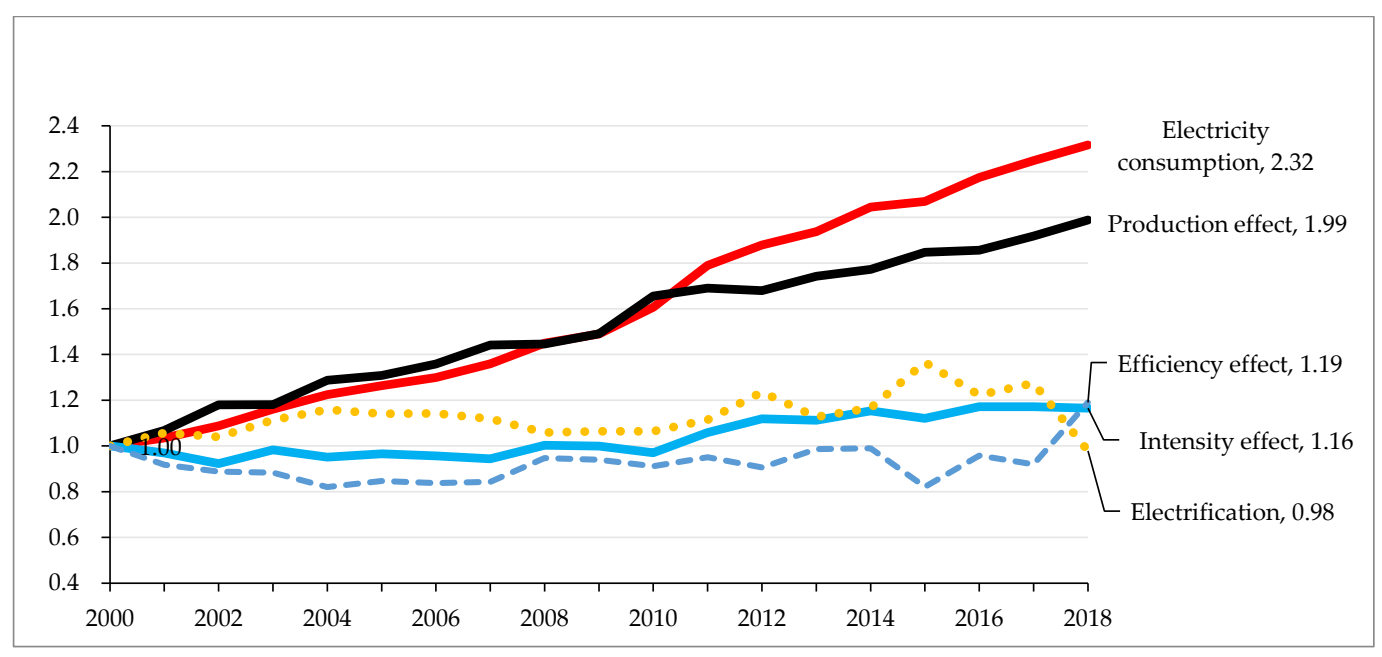

Figure A4. Petrochemical electricity consumption LMDI results (fixed base year, multiplicative). 


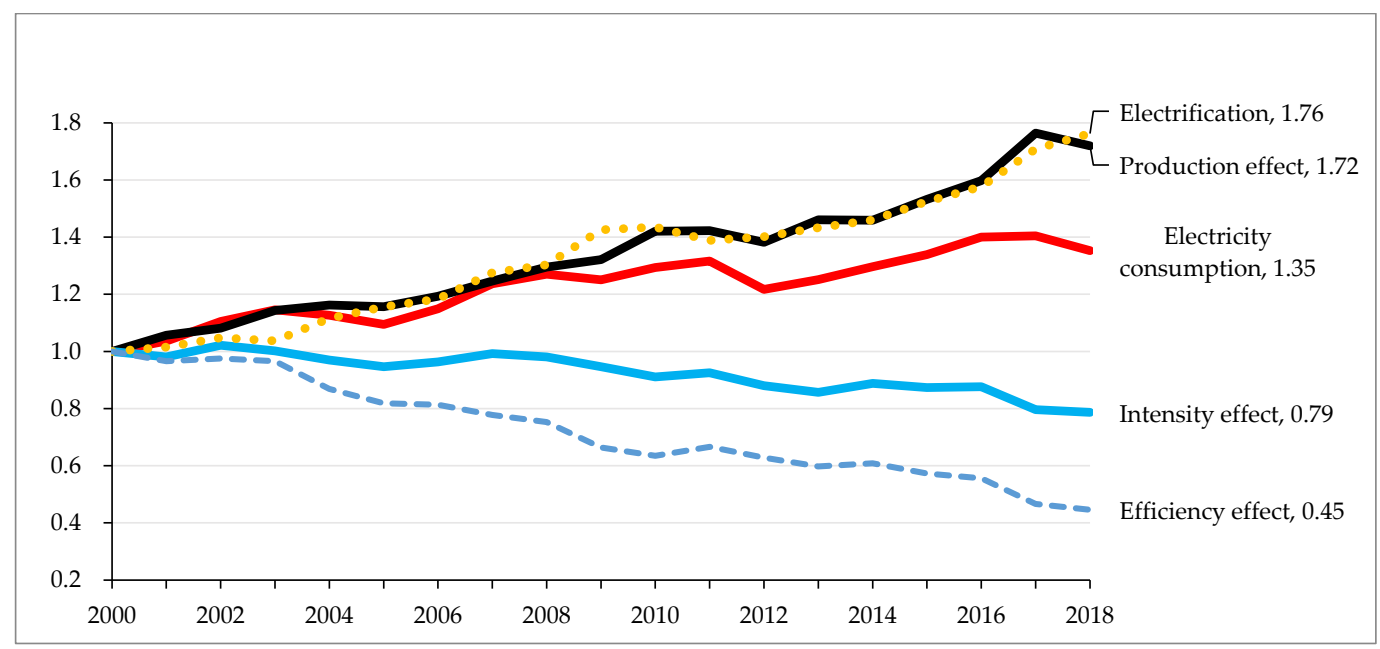

Figure A5. Nonmetallic electricity consumption LMDI results (fixed base year, multiplicative).

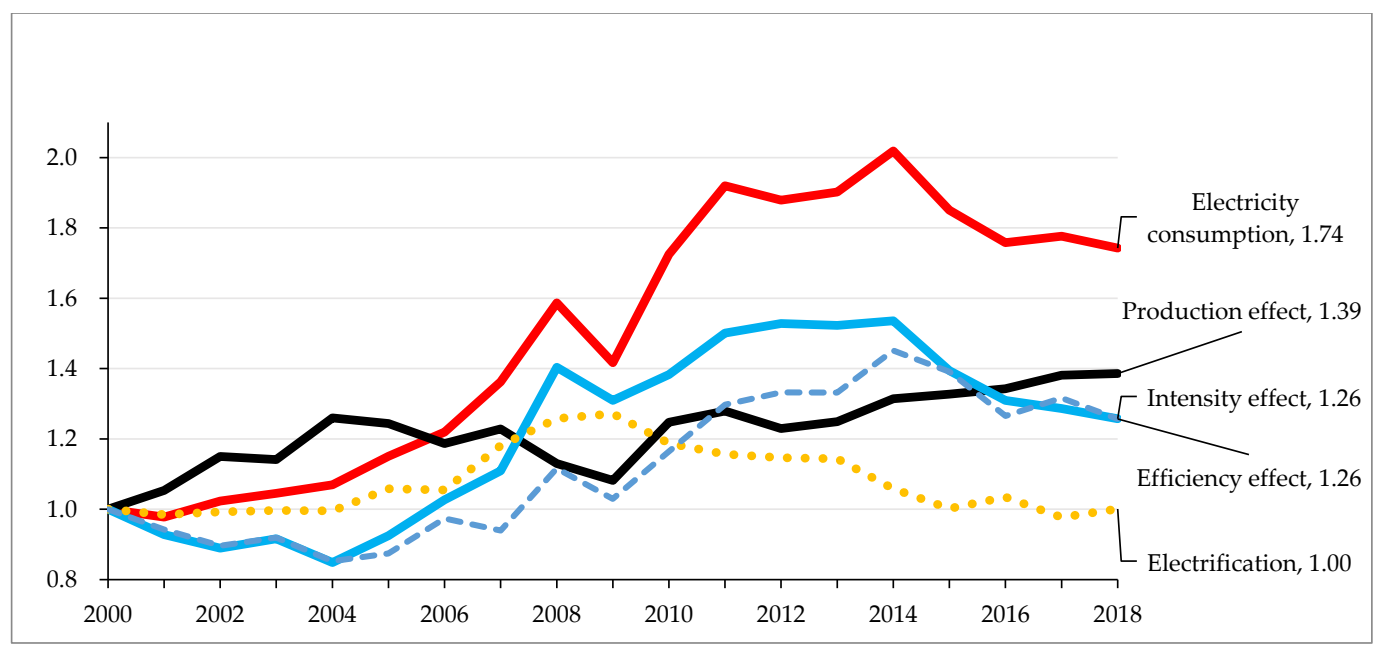

Figure A6. Basic metal electricity consumption LMDI results (fixed base year, multiplicative).

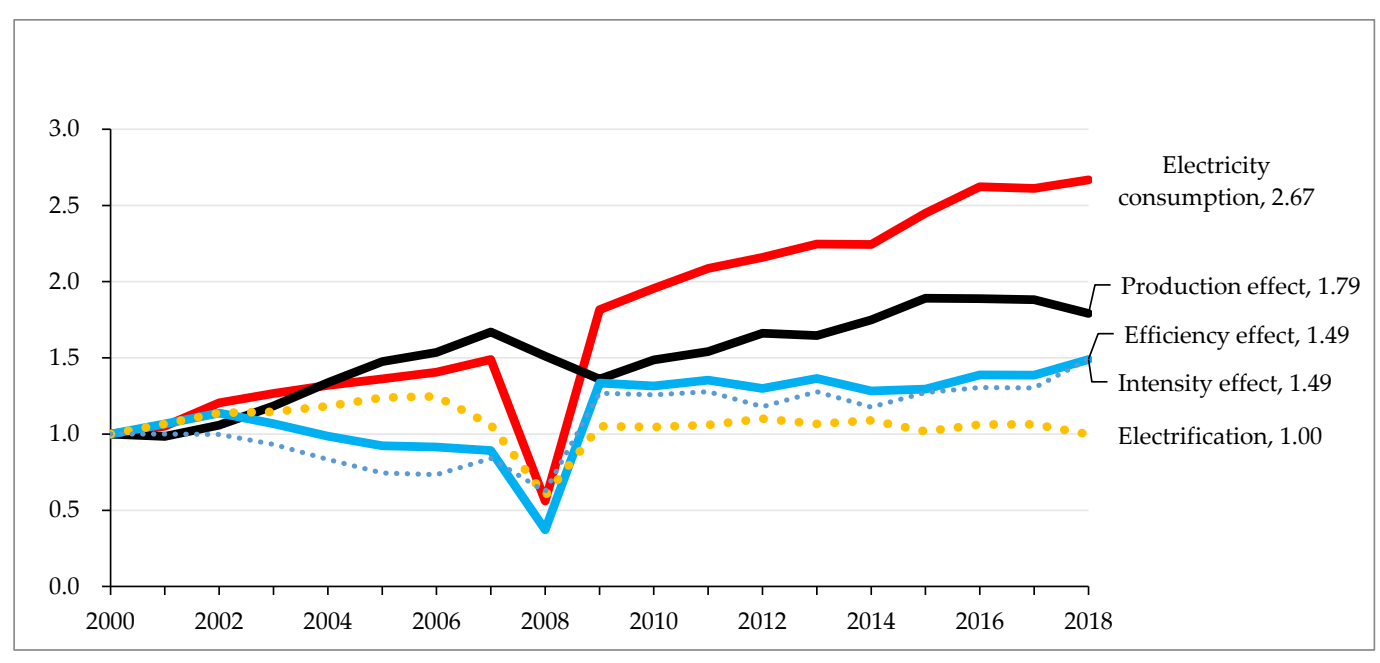

Figure A7. Nonferrous metal electricity consumption LMDI results (fixed base year, multiplicative). 


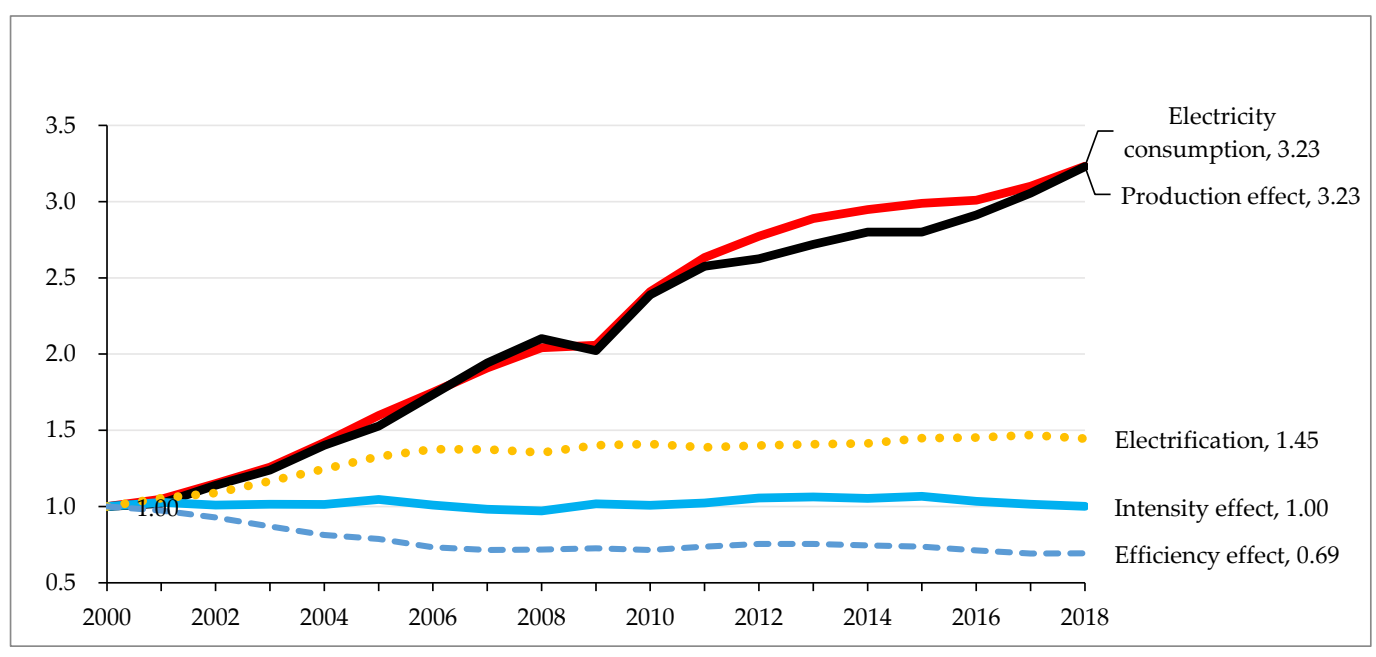

Figure A8. Fabricated metal electricity consumption LMDI results (fixed base year, multiplicative).

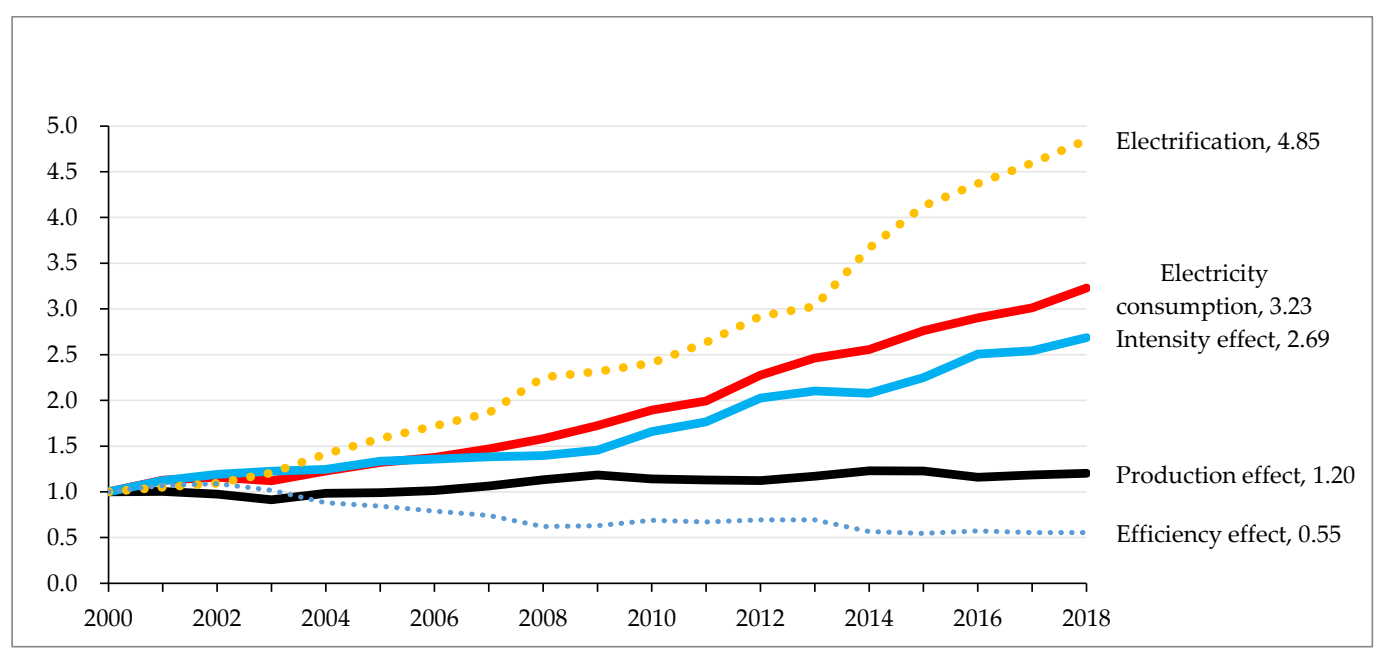

Figure A9. Agriculture/forestry/fishing electricity consumption LMDI results (fixed base year, multiplicative).

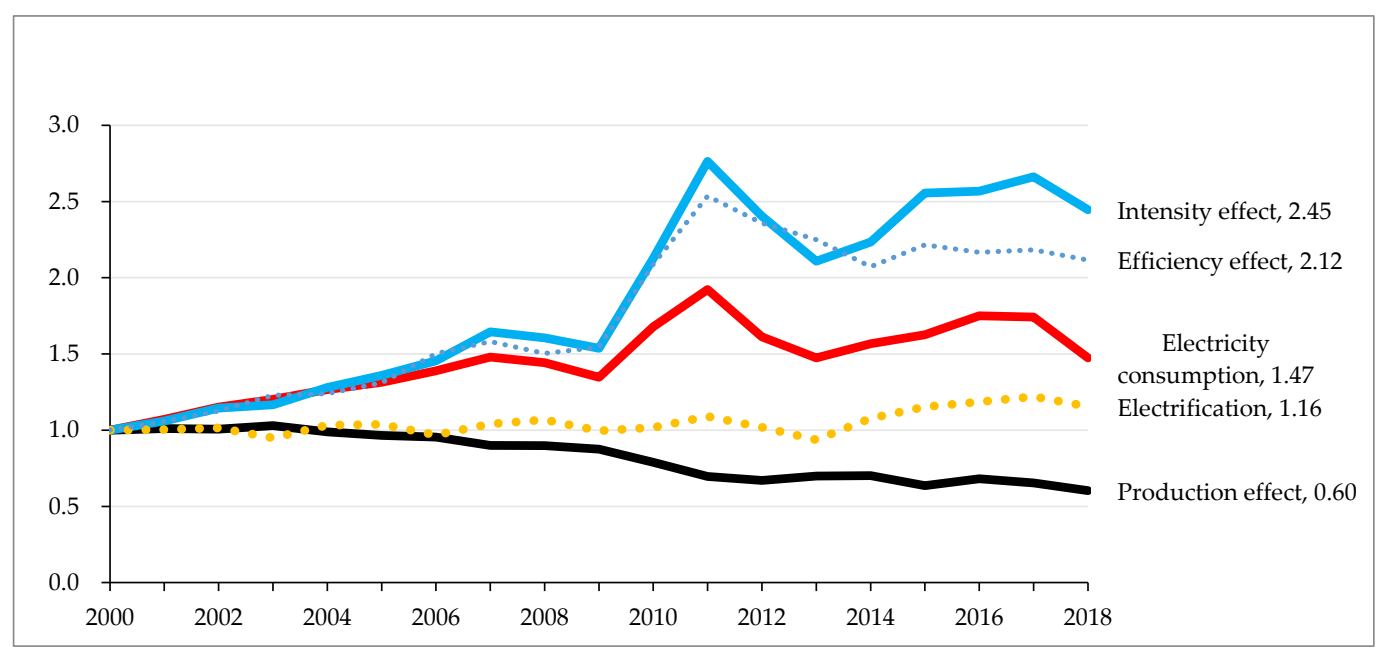

Figure A10. Mining and quarrying electricity consumption LMDI results (fixed base year, multiplicative). 


\section{References}

1. Savaresi, A. The Paris Agreement: A new beginning? J. Energy Nat. Resour. Law 2016, 34, 16-26. [CrossRef]

2. Oh, H.; Hong, I.; Oh, I. South Korea's 2050 Carbon Neutrality Policy. East. Asian Policy 2021, 13, 33-46. [CrossRef]

3. IPCC. Climate Change 2014: Synthesis Report. Contribution of Working Groups I, II and III to the Fifth Assessment Report of the Intergovernmental Panel on Climate Change; Pachauri, R.K., Meyer, L.A., Eds.; IPCC: Geneva, Switzerland, 2014.

4. Lee, S.-Y. Existing and anticipated technology strategies for reducing greenhouse gas emissions in Korea's petrochemical and steel industries. J. Clean. Prod. 2013, 40, 83-92. [CrossRef]

5. Nyberg, F. Predictors of Climate Change Risk Perceptions among Finns. Master's Thesis, University of Helsinki, Helsinki, Finland, 2021.

6. Obrist, M.D.; Kannan, R.; Schmidt, T.J.; Kober, T. Decarbonization pathways of the Swiss cement industry towards net zero emissions. J. Clean. Prod. 2021, 288, 125413. [CrossRef]

7. IEA. Energy Efficiency is the First Fuel, and Demand for It Needs to Grow; IEA: Paris, France, 2019.

8. Reddy, B.S. Barriers and drivers to energy efficiency-A new taxonomical approach. Energy Convers. Manag. 2013, 74, 403-416. [CrossRef]

9. Cattaneo, C. Internal and external barriers to energy efficiency: Which role for policy interventions? Energy Effic. 2019, 12, 1293-1311. [CrossRef]

10. EC. A Clean Planet for All: A European Long-Term Strategic Vision for A Prosperous, Modern, Com-Petitive and Climate Neutral Economy; European Commission: Brussels, Belgium, 2018.

11. Jin, X.; Baker, K.; Christensen, D.; Isley, S. Foresee: A user-centric home energy management system for energy efficiency and demand response. Appl. Energy 2017, 205, 1583-1595. [CrossRef]

12. IRENA. CPI Global Landscape of Renewable Energy Finance 2020; International Renewable Energy Agency: Abu Dhabi, United Arab Emirates, 2020.

13. Ang, B.; Zhang, F.; Choi, K.-H. Factorizing changes in energy and environmental indicators through decomposition. Energy 1998, 23, 489-495. [CrossRef]

14. Kim, S. LMDI Decomposition Analysis of Energy Consumption in the Korean Manufacturing Sector. Sustainability 2017, 9, 202. [CrossRef]

15. Choi, K.-H.; Oh, W. Extended Divisia index decomposition of changes in energy intensity: A case of Korean manufacturing industry. Energy Policy 2014, 65, 275-283. [CrossRef]

16. Park, S.; Kim, J. A Comparison of Decomposition Analyses for Primary and Final Energy Consumption of Korea. Environ. Resour. Econ. Rev. 2014, 23, 305-330. [CrossRef]

17. Jin, T.; Choi, B. Sectoral Decomposition of Korea's Energy Consumption by Global Value Chain Dimensions. Sustainability 2020, 12, 8483. [CrossRef]

18. Kim, J. A review on energy decomposition analysis in Korea. Korean Energy Econ. Rev. 2015, 14, $265-291$.

19. Lee, J.; Kim, J. A Decomposition Analysis of the Korean Manufacturing Sector: Monetary vs. Physical Outputs. Sustainability 2021, 13, 6192. [CrossRef]

20. Oh, I.; Wehrmeyer, W.; Mulugetta, Y. Decomposition analysis and mitigation strategies of CO2 emissions from energy consumption in South Korea. Energy Policy 2010, 38, 364-377. [CrossRef]

21. Jeong, K.; Kim, S. LMDI decomposition analysis of greenhouse gas emissions in the Korean manufacturing sector. Energy Policy 2013, 62, 1245-1253. [CrossRef]

22. Balezentis, T. Shrinking ageing population and other drivers of energy consumption and $\mathrm{CO} 2$ emission in the residential sector: A case from Eastern Europe. Energy Policy 2020, 140, 111433. [CrossRef]

23. Su, W.; Wang, Y.; Streimikiene, D.; Balezentis, T.; Zhang, C. Carbon dioxide emission decomposition along the gradient of economic development: The case of energy sustainability in the G7 and Brazil, Russia, India, China and South Africa. Sustain. Dev. 2019, 28, 657-669. [CrossRef]

24. British Petroleum (BP). BP Statistical Review 2019; BP: London, UK, 2019.

25. Xu, J.-H.; Fleiter, T.; Eichhammer, W.; Fan, Y. Energy consumption and CO2 emissions in China's cement industry: A perspective from LMDI decomposition analysis. Energy Policy 2012, 50, 821-832. [CrossRef]

26. Wang, W.; Liu, X.; Zhang, M.; Song, X. Using a new generalized LMDI (logarithmic mean Divisia index) method to analyze China's energy consumption. Energy 2014, 67, 617-622. [CrossRef]

27. Wang, M.; Feng, C. Decomposing the change in energy consumption in China's nonferrous metal industry: An empirical analysis based on the LMDI method. Renew. Sustain. Energy Rev. 2018, 82, 2652-2663. [CrossRef]

28. Sun, X.; Liu, X. Decomposition analysis of debt's impact on China's energy consumption. Energy Policy 2020, 146, 111802. [CrossRef]

29. Achour, H.; Belloumi, M. Decomposing the influencing factors of energy consumption in Tunisian transportation sector using the LMDI method. Transp. Policy 2016, 52, 64-71. [CrossRef]

30. Akyürek, Z. LMDI decomposition analysis of energy consumption of Turkish manufacturing industry: 2005-2014. Energy Effic. 2020, 13, 649-663. [CrossRef]

31. Bianco, V. Analysis of electricity consumption in the tourism sector. A decomposition approach. J. Clean. Prod. 2020, 248, 119286. [CrossRef] 
32. González, P.F.; Landajo, M.; Presno, M.J. Multilevel LMDI decomposition of changes in aggregate energy consumption. A cross country analysis in the EU-27. Energy Policy 2014, 68, 576-584. [CrossRef]

33. Chen, X.; Shuai, C.; Zhang, Y.; Wu, Y. Decomposition of energy consumption and its decoupling with economic growth in the global agricultural industry. Environ. Impact Assess. Rev. 2020, 81, 106364. [CrossRef]

34. Gillingham, K.T.; Knittel, C.R.; Li, J.; Ovaere, M.; Reguant, M. The Short-run and Long-run Effects of Covid-19 on Energy and the Environment. Joule 2020, 4, 1337-1341. [CrossRef]

35. Santiago, I.; Moreno-Munoz, A.; Quintero-Jiménez, P.; Garcia-Torres, F.; Gonzalez-Redondo, M. Electricity demand during pandemic times: The case of the COVID-19 in Spain. Energy Policy 2021, 148, 111964. [CrossRef]

36. Szmigiera, M. GDP Loss Due to COVID-19, by Economy 2020. 2021. Available online: https://www.statista.com/statistics/1240 594/gdp-loss-covid-19-economy / (accessed on 10 July 2021).

37. KEEI. Korean Energy Balances; KEEI: Ulsan, Korea, 2020.

38. Korean Statistical Information Service (KOSIS) GDP and GNI by Economic Activity. Available online: https://kosis.kr (accessed on 11 August 2020).

39. Sun, J. Changes in energy consumption and energy intensity: A complete decomposition model. Energy Econ. 1998, 20, 85-100. [CrossRef]

40. Hoekstra, R.; Bergh, J.C.V.D. Comparing structural decomposition analysis and index. Energy Econ. 2003, 25, 39-64. [CrossRef]

41. Ang, B. The LMDI approach to decomposition analysis: A practical guide. Energy Policy 2005, 33, 867-871. [CrossRef]

42. Ang, B. Decomposition of industrial energy consumption: The energy intensity approach. Energy Econ. 1994, 16, 163-174. [CrossRef]

43. Ang, B.W.; Choi, K.-H. Decomposition of Aggregate Energy and Gas Emission Intensities for Industry: A Refined Divisia Index Method. Energy J. 1997, 18, 59-73. [CrossRef]

44. Ang, B.; Liu, N. Negative-value problems of the logarithmic mean Divisia index decomposition approach. Energy Policy 2007, 35, 739-742. [CrossRef]

45. Ang, B.; Liu, N. Handling zero values in the logarithmic mean Divisia index decomposition approach. Energy Policy 2007, 35, 238-246. [CrossRef]

46. Ang, B. LMDI decomposition approach: A guide for implementation. Energy Policy 2015, 86, 233-238. [CrossRef]

47. Ang, B.; Liu, F. A new energy decomposition method: Perfect in decomposition and consistent in aggregation. Energy 2001, 26, 537-548. [CrossRef]

48. Han, J. LMDI Decomposition Analysis for Electricity Consumption in Korean Manufacturing. J. Energy Eng. 2015, 24, 137-148. [CrossRef] 